\title{
Physical Properties \\ of $\left(\mathrm{M}_{2} \mathrm{Cu}_{2} \mathrm{O}_{3}\right)_{m}\left(\mathrm{CuO}_{2}\right)_{n}(\mathrm{M}=\mathrm{Ca}, \mathrm{Sr}, \mathrm{Bi})$ Single Crystals with Bi-2212 Phase on their Surface
}

\author{
G.-J. BABONAS ${ }^{a, *}$, L. LeONYUK $^{b}$, V. MALTSEV ${ }^{b}$,

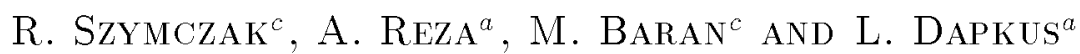 \\ ${ }^{a}$ Semiconductor Physics Institute, 2600 Vilnius, Lithuania \\ ${ }^{b}$ Moscow State University, 119899, Moscow, Russia \\ 'Institute of Physics, Polish Academy of Sciences \\ Al. Lotników 32/46, 02-668 Warsaw, Poland
}

(Received June 27, 2001)

The structural, optical, and magnetic properties are studied in the $\left(\mathrm{M}_{2} \mathrm{Cu}_{2} \mathrm{O}_{3}\right)_{m}\left(\mathrm{CuO}_{2}\right)_{n}$-type single crystals with the surface on which the Bi-2212-type phase was indicated. The physical properties of such samples were interpreted to some extent by the contributions of two phases. When the secondary phases on the surface of the samples were removed by mechanical polishing or etching by $\mathrm{Ar}^{+}$-ion plasma, the physical properties were typical of the $\left(\mathrm{M}_{2} \mathrm{Cu}_{2} \mathrm{O}_{3}\right)_{m}\left(\mathrm{CuO}_{2}\right)_{n}$-type crystals. The optical method was shown to be effective for indication of secondary Bi-rich phases on the surface of $\left(\mathrm{M}_{2} \mathrm{Cu}_{2} \mathrm{O}_{3}\right)_{m}\left(\mathrm{CuO}_{2}\right)_{n}$ samples.

PACS numbers: 78.66.-w, 74.72.Jt, 74.76.Bz

\section{Introduction}

During last several years the $\left(\mathrm{M}_{2} \mathrm{Cu}_{2} \mathrm{O}_{3}\right)_{m}\left(\mathrm{CuO}_{2}\right)_{n}$ compounds were widely studied. Specific magnetic $[1,2]$ and optical $[3,4]$ properties and superconductivity [5-7] (predicted theoretically [8] in spin-ladder cuprates) were investigated. The

*corresponding author; e-mail: jgb@uj.pfi.lt 
experimental results have shown that $\left(\mathrm{M}_{2} \mathrm{Cu}_{2} \mathrm{O}_{3}\right)_{7}\left(\mathrm{CuO}_{2}\right)_{10}(\mathrm{M}=\mathrm{Ca}, \mathrm{Sr})$ compounds obtained by a solid-state synthesis [5] or by floating zone method $[7,9]$ were superconducting with $T_{\mathrm{C}}$-values around $9-12 \mathrm{~K}$ at high pressures of $3-4.5 \mathrm{GPa}$ with the superconducting volume fraction of about $5 \%$. In the crystalline rod obtained by the floating zone method, the impurity phases of $\mathrm{SrCuO}_{2}$ and $\mathrm{CuO}$ or even more complex intergrowths of $\left(\mathrm{M}_{2} \mathrm{Cu}_{2} \mathrm{O}_{3}\right)_{m}\left(\mathrm{CuO}_{2}\right)_{n}$ with $\mathrm{Ca}_{2} \mathrm{CuO}_{3}$ and $(\mathrm{Sr}, \mathrm{Ca}) \mathrm{CuO}_{2}$ were observed [10] in agreement with the phase diagram for the $\mathrm{SrO}-\mathrm{CuO}$ system [11]. In the samples obtained by the floating zone method the investigation of the intergrowth is very difficult because the growth surfaces of various single crystalline fragments are distorted and masked due to particular features of this growth technique.

In contrast to the samples obtained by the floating zone technique, the single crystals of $\left(\mathrm{M}_{2} \mathrm{Cu}_{2} \mathrm{O}_{3}\right)_{5}\left(\mathrm{CuO}_{2}\right)_{7}(\mathrm{M}=\mathrm{Ca}, \mathrm{Sr}, \mathrm{Bi})$ grown from the melt were superconducting at $T_{\mathrm{c}} \sim 80 \mathrm{~K}$ at ambient pressures with the superconducting volume fraction up to $40 \%[6,12]$. In order to reduce the probability of the formation of subsidiary phases, the maximum temperature was decreased by adding flux $\mathrm{Bi}_{2} \mathrm{CuO}_{4}$ into the melt and using the "melted band" technique [13]. However, in some incidental cases the Bi-rich phases 2212 and 2201 were noticed [14] on the surface of $\left(\mathrm{M}_{2} \mathrm{Cu}_{2} \mathrm{O}_{3}\right)_{m}\left(\mathrm{CuO}_{2}\right)_{n}$-type crystals. The preliminary investigations have shown [13] that subsidiary phases on the crystal surface can be removed by polishing. Detailed studies of the phase formation have shown [14] that an epitaxial-like intergrowth between $\left(\mathrm{M}_{2} \mathrm{Cu}_{2} \mathrm{O}_{3}\right)_{m}\left(\mathrm{CuO}_{2}\right)_{n}$-type and Bi-rich phases does not occur but rather a "nut-shell"-like crust of a secondary phase is formed. In this respect, the studies of the $\left(\mathrm{M}_{2} \mathrm{Cu}_{2} \mathrm{O}_{3}\right)_{m}\left(\mathrm{CuO}_{2}\right)_{n}$-type samples containing secondary Bi-rich phases are principally important for investigation of superconductivity in ladder-type cuprates.

In the present work investigations were provided on the $\left(\mathrm{M}_{2} \mathrm{Cu}_{2} \mathrm{O}_{3}\right)_{m}\left(\mathrm{CuO}_{2}\right)_{n}$ single crystals with the surface on which the Bi-2212-type phase was indicated by $\mathrm{X}$-ray diffraction (XRD). The studies have shown that magnetic, structural, and optical properties can indicate with confidence the presence of the Bi-2212-type phases on the surface of the $\left(\mathrm{M}_{2} \mathrm{Cu}_{2} \mathrm{O}_{3}\right)_{m}\left(\mathrm{CuO}_{2}\right)_{n}$-type crystals. The physical parameters of such samples can be to some extent interpreted as the sum of contributions of two phases under consideration.

\section{Experimental}

The single crystals investigated in the present work have been grown from the melt with the $\mathrm{Bi}_{2} \mathrm{CuO}_{4}$ flux. The "melted-band" method [13] was mainly used. The $\left(\mathrm{M}_{2} \mathrm{Cu}_{2} \mathrm{O}_{3}\right)_{m}\left(\mathrm{CuO}_{2}\right)_{n}$-type single crystals were obtained from a partially melted Bi-containing load at the maximum temperatures below $960^{\circ} \mathrm{C}$. As a whole, the decanting of the melt can be used to avoid the formation of co-crystallizing phases [15]. However, in some experimental runs the Bi-based 
2201- or 2212-type phases and $\mathrm{Bi}_{4} \mathrm{Sr}_{8} \mathrm{Cu}_{5} \mathrm{O}_{20}$ deposited from the evaporating melt in the shape of drops or islands of a film were indicated on the surface of the $\left(\mathrm{M}_{2} \mathrm{Cu}_{2} \mathrm{O}_{3}\right)_{m}\left(\mathrm{CuO}_{2}\right)_{n}$-type single crystals. The characterization of the secondary phases by electron probe microanalysis (EPMA) meets difficulties because of a small thickness of these formations. Therefore, an application of various methods is useful for a characterization of complex samples.

Some characteristics of the investigated samples are presented in the Table. The samples from the series 1446 and 1427 were grown by the "melted band" method [13]. The size of the samples was of the order of $0.2 \times 0.5 \times 3 \mathrm{~mm}$. The grown single crystals were studied previously [16] by XRD using a four-circle INEL diffractometer for powder analysis and a diffractometer CAD4 Enraf-Nonius for a single crystal refinement. The chemical composition was determined by EPMA using JSM-5800LV.

TABLE

Some characteristics of the investigated $\left(\mathrm{M}_{2} \mathrm{Cu}_{2} \mathrm{O}_{3}\right)_{5}\left(\mathrm{CuO}_{2}\right)_{7}$-type single crystals.

\begin{tabular}{c|c|c|c}
\hline \hline Sample & Composition & $T_{\mathrm{c}}[\mathrm{K}]$ & Indication of Bi-2212 phase \\
\hline 1446 & $\left(\mathrm{Ca}_{5.2} \mathrm{Sr}_{4.5} \mathrm{Bi}_{0.3}\right) \mathrm{Cu}_{17.0} \mathrm{O}_{x}$ & 84 & $(a c)$-plane \\
1427 & $\left(\mathrm{Ca}_{5.4} \mathrm{Sr}_{3.9} \mathrm{Bi}_{0.7}\right) \mathrm{Cu}_{15.3} \mathrm{O}_{x}$ & $\sim 80$ & $(b c)$-plane \\
$800^{*}$ & $\left(\mathrm{Ca}_{4.86} \mathrm{Sr}_{4.42} \mathrm{Bi}_{0.05}\right) \mathrm{Cu}_{17} \mathrm{O}_{29}$ & 84 & $(b c)$-plane \\
\hline
\end{tabular}

*Lattice parameters $[\AA]: a=11.349(7), b=12.896(5), c=19.49(3)$

X-ray investigations were carried out with a resolution better than $0.01^{\circ}$ on a modified double-crystal diffractometer DRON-4-07 with $\mathrm{Cu} K_{\alpha 1}$ radiation $(\lambda=1.5405 \AA)$ using the $(n,-n)$ nondispersive Bragg arrangement and a quartz-crystal as a monochromator.

The temperature dependences of magnetic susceptibility of as-grown crystals and the samples etched by $\mathrm{Ar}^{+}$-ion plasma were studied using a SQUID magnetometer MPMS-5, quantum design. The optical spectra were measured by spectroscopic ellipsometry method in the range of $0.5-5.0 \mathrm{eV}$ making use of a photometric ellipsometer with rotating analyzer. It should be noted that the optical data were obtained from the most homogeneous part of the sample surface using a light spot of ca. $0.5 \mathrm{~mm}$.

\section{Results and discussion}

The results of experimental investigations on the structural, optical, and magnetic properties of $\left(\mathrm{M}_{2} \mathrm{Cu}_{2} \mathrm{O}_{3}\right)_{m}\left(\mathrm{CuO}_{2}\right)_{n}$-type single crystals with Bi-rich phases on the sample surface will be presented and discussed. 


\subsection{Structural studies}

The presence of $\mathrm{Bi}-2212$ layer on the surface of several $\left(\mathrm{M}_{2} \mathrm{Cu}_{2} \mathrm{O}_{3}\right)_{m}\left(\mathrm{CuO}_{2}\right)_{n^{-}}$ -type single crystals was indicated by XRD studies. In the as-grown samples two reflections were observed in the region of $2 \Theta=29.2^{\circ}$ and $2 \Theta=31.5^{\circ}$. The second reflection is the 4 th order of the inter-plane spacing in [100] direction corresponding to the lattice $a$-parameter $(\sim 11.3 \AA$, see the Table) of the $\left(\mathrm{M}_{2} \mathrm{Cu}_{2} \mathrm{O}_{3}\right)_{m}\left(\mathrm{CuO}_{2}\right)_{n}$-type phase. The first reflection is due to the 10 th order of the inter-plane spacing $30.5 \AA$ and it is in agreement with the lattice $c$-parameter for Bi-2212-type compound.

Figure 1 shows the rocking curves obtained for the sample 800 . The width of the reflection due to $\mathrm{Bi}-2212$-type phase is about 2 times larger than that due to $\left(\mathrm{M}_{2} \mathrm{Cu}_{2} \mathrm{O}_{3}\right)_{m}\left(\mathrm{CuO}_{2}\right)_{n}$-type phase. It is conditioned by a better structural perfection of the latter. A different intensity of reflections shows that the XRD pattern is caused mainly by the ladder-type compound $\left(\mathrm{M}_{2} \mathrm{Cu}_{2} \mathrm{O}_{3}\right)_{m}\left(\mathrm{CuO}_{2}\right)_{n}$.
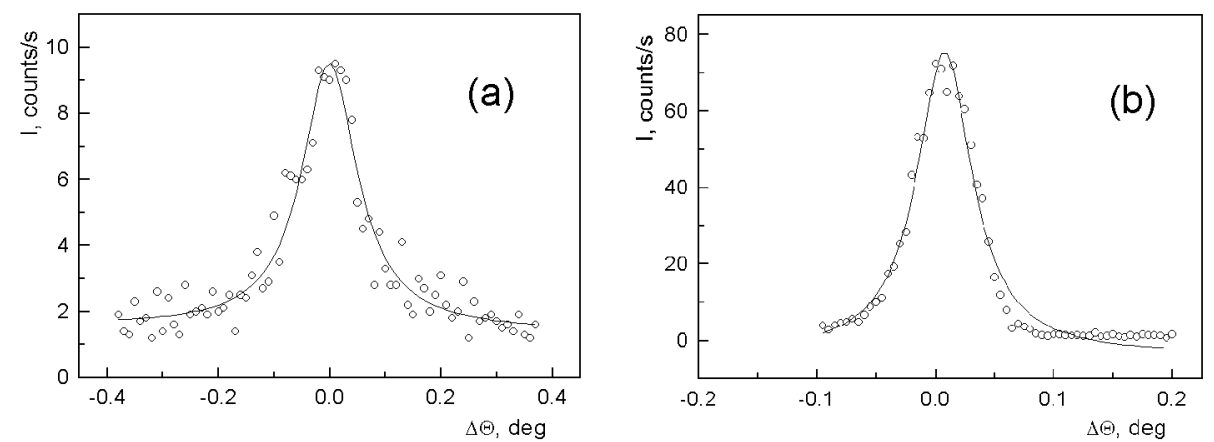

Fig. 1. The rocking curves obtained from the surface of as-grown sample 800 indicating the reflections due to $\mathrm{Bi}-2212$ (a) and $\left(\mathrm{M}_{2} \mathrm{Cu}_{2} \mathrm{O}_{3}\right)_{m}\left(\mathrm{CuO}_{2}\right)_{n}$-type (b) phases. The experimental data (points) were fitted by Lorentzian-shape lines.

When the sample surface was polished by removing the surface layer of about $1 \mu \mathrm{m}$ thick, the XRD pattern was significantly changed: (i) the reflection due to Bi-2212-type phase disappeared; (ii) the intensity of the reflection corresponding to the $a$-parameter of the $\left(\mathrm{M}_{2} \mathrm{Cu}_{2} \mathrm{O}_{3}\right)_{m}\left(\mathrm{CuO}_{2}\right)_{n}$-type phase was increased by several times. These observations showed that the $\mathrm{Bi}-2212$ phase was removed from the surface of the $\left(\mathrm{M}_{2} \mathrm{Cu}_{2} \mathrm{O}_{3}\right)_{m}\left(\mathrm{CuO}_{2}\right)_{n}$-type single crystal. The optical spectra of polished sample [13] were typical of the $\left(\mathrm{M}_{2} \mathrm{Cu}_{2} \mathrm{O}_{3}\right)_{m}\left(\mathrm{CuO}_{2}\right)_{n}$-type phase [17].

The sample 1446 was investigated both with as-grown surface as well as after the surface layer was removed by ion-etching. The ion-etching was done using the beam of $\mathrm{Ar}^{+}$ions of the energy $1.6 \mathrm{keV}$ and the sample was rotated with respect to the ion beam to remove possible Bi-2212 layers from all the sample surfaces. No reflection of the Bi-2212-type phase was found in the XRD pattern of ion-etched 
sample. However, after the ion milling the sample surfaces were damaged and were not good enough for careful optical studies. Therefore, only the magnetic data for ion-etched sample 1446 will be discussed below.

It should be noted that the presence of the Bi-2212-type layer was indicated both on $(b c)$ and $(a c)$-planes of the $\left(\mathrm{M}_{2} \mathrm{Cu}_{2} \mathrm{O}_{3}\right)_{m}\left(\mathrm{CuO}_{2}\right)_{n}$-type single crystals (Table). In both cases the $c$-axis of the $\mathrm{Bi}-2212$-type layer was perpendicular to the sample surface.

\subsection{Optical spectra}

The results of ellipsometric measurements for the $\left(\mathrm{M}_{2} \mathrm{Cu}_{2} \mathrm{O}_{3}\right)_{m}\left(\mathrm{CuO}_{2}\right)_{n}$ samples with a secondary Bi-2212 phase on the surface were considered in the pseudodielectric function (PDF) $\langle\varepsilon\rangle$ approximation [18]. The PDF $\langle\varepsilon\rangle$ was obtained considering the anisotropic crystal as isotropic one. In the two-phase (ambientsample) model:

$$
\langle\varepsilon\rangle=\sin ^{2} \theta\left[\left(\frac{1-\rho}{1+\rho}\right)^{2} \tan ^{2} \theta+1\right],
$$

where $\rho=r_{p} / r_{s}=\tan \Psi \exp (\mathrm{i} \Delta)$ is the complex reflection, $r_{p}, r_{s}$ are the Fresnel reflection coefficients, $\Psi=\left|r_{p} / r_{s}\right|, \Delta=\left(\delta_{r p}-\delta_{i p}\right)-\left(\delta_{r s}-\delta_{i s}\right)$ are ellipsometric parameters, $\delta_{k l}$ is the phase of reflected $(k=r)$ or incident $(k=i)$ light polarized parallel $(l=p)$ or perpendicular $(l=s)$ to the plane of light incidence, and $\theta$ is the angle of light incidence. The ellipsometric measurements were made in symmetric experimental geometry, at which the reflection matrix for the single crystals of orthorhombic symmetry was diagonal [19].

In the pseudodielectric function approximation, the main contribution to the optical response of the anisotropic crystal originates from the projection of the dielectric tensor onto the line of intersection between surface and the plane of light incidence. Therefore, the contribution of Bi-2212 was assumed to arise from the dielectric tensor components perpendicular to $c$-axis. The lattice parameter determined $(c \approx 30.5 \AA$ ) was typical of the Bi-2212 crystals of tetragonal symmetry. Taking into account these two arguments, the contribution of the Bi-2212 phase was considered as isotropic media modeling the optical response of the sample with surface layer. The data for superconducting or non-superconducting Bi-2212 crystals [20] were taken into account. In the latter case, the additional contribution of free carriers modeled by Drude-like term was taken into account.

The optical data were interpreted in two models. In the first model the formation of complete thin film of Bi-2010-type phase on the single crystal of $\left(\mathrm{M}_{2} \mathrm{Cu}_{2} \mathrm{O}_{3}\right)_{m}\left(\mathrm{CuO}_{2}\right)_{n}$ was considered. In three-component (ambient-filmsubstrate) system the ratio $\rho$ of the complex amplitude reflection coefficients $R_{p}$ and $R_{s}$ is as follows [19]:

$$
\rho=\frac{R_{p}}{R_{s}}=\tan \Psi \exp (j \Delta)=\tan \Psi(\cos \Delta+j \sin \Delta),
$$


where

$$
R_{p}=\frac{r_{01 p}+r_{12 p} \exp (-j 2 \beta)}{1+r_{01 p} r_{12 p} \exp (-j 2 \beta)}, \quad R_{s}=\frac{r_{01 s}+r_{12 s} \exp (-j 2 \beta)}{1+r_{01 s} r_{12 s} \exp (-j 2 \beta)},
$$

$r_{01 p}, r_{01 s}$ and $r_{12 p}, r_{12 s}$ are the Fresnel reflection coefficients for interfaces ambientfilm (0-1) and film-substrate (1-2), respectively, and the phase of the film of thickness $d$ is

$$
\beta=2 \pi\left(\frac{d}{\lambda}\right)\left(N_{1}^{2}-N_{0}^{2} \sin ^{2} \phi_{0}\right)^{1 / 2},
$$

where $\phi_{0}$ is the angle of incidence in ambient and $N_{0}, N_{1}$ are refractive indexes for ambient and film, respectively. The refractive index of film $N_{1}$ is assumed to be a complex quantity.

The Fresnel coefficients for the interface $0-1$ for isotropic film with dielectric constant $\varepsilon_{1}$ and isotropic ambient with $N_{0}=1$ are

$$
\begin{aligned}
& r_{01 p}=\frac{\varepsilon_{1} \cos \phi_{0}-\left(\varepsilon_{1}-\sin ^{2} \phi_{0}\right)^{1 / 2}}{\varepsilon_{1} \cos \phi_{0}+\left(\varepsilon_{1}-\sin ^{2} \phi_{0}\right)^{1 / 2}} \\
& r_{01 s}=\frac{\cos \phi_{0}-\left(\varepsilon_{1}-\sin ^{2} \phi_{0}\right)^{1 / 2}}{\cos \phi_{0}+\left(\varepsilon_{1}-\sin ^{2} \phi_{0}\right)^{1 / 2}} .
\end{aligned}
$$

Let us consider the interface 1-2 between the isotropic media with the dielectric constant $\varepsilon_{1}$ and biaxial orthorhombic crystal $\left(\varepsilon_{a} \neq \varepsilon_{b} \neq \varepsilon_{c}\right)$ in the experimental geometry with the crystal symmetry $i$-axis normal to the surface plane and $j$-axis in the plane of light incidence. In this case the reflectance matrix is diagonal and the Fresnel coefficients are expressed by the following equations:

$$
\begin{aligned}
& r_{12 p}=\frac{\sqrt{\varepsilon_{i}} \sqrt{\varepsilon_{j}} \cos \phi_{1}-\sqrt{\varepsilon_{1}}\left(\varepsilon_{i}-\varepsilon_{1} \sin ^{2} \phi_{1}\right)^{1 / 2}}{\sqrt{\varepsilon_{i}} \sqrt{\varepsilon_{j}} \cos \phi_{1}+\sqrt{\varepsilon_{1}}\left(\varepsilon_{i}-\varepsilon_{1} \sin ^{2} \phi_{1}\right)^{1 / 2}}, \\
& r_{12 s}=\frac{\sqrt{\varepsilon_{1}} \cos \phi_{1}-\left(\varepsilon_{k}-\varepsilon_{1} \sin ^{2} \phi_{1}\right)^{1 / 2}}{\sqrt{\varepsilon_{1}} \cos \phi_{1}+\left(\varepsilon_{k}-\varepsilon_{1} \sin ^{2} \phi_{1}\right)^{1 / 2}},
\end{aligned}
$$

where $i=a, b, c, j=a, b, c, k=a, b, c, i \neq j \neq k \neq i$ and $\phi_{1}$ is the angle of incidence at the interface 1-2.

Taking into account the relationship between the angles of incidence in the system

$$
\cos \phi_{1}=\frac{1}{N_{1}}\left(N_{1}^{2}-N_{0}^{2} \sin ^{2} \phi_{0}\right)^{1 / 2},
$$

the experimental data for the single crystals of $\left(\mathrm{M}_{2} \mathrm{Cu}_{2} \mathrm{O}_{3}\right)_{m}\left(\mathrm{CuO}_{2}\right)_{n}$ with a surface layer of Bi-2212-type phase can be described by the equations presented above. The data of the dielectric tensor for $\left(\mathrm{M}_{2} \mathrm{Cu}_{2} \mathrm{O}_{3}\right)_{m}\left(\mathrm{CuO}_{2}\right)_{n}$ were taken from [17]. 
Figure 2 shows the experimental data for the sample 1446 which were described by the model of complete surface film of Bi-2212-type phase. As is seen, the modeled spectra can be satisfactorily fitted to experimental data taking the film thickness as a fitting parameter.
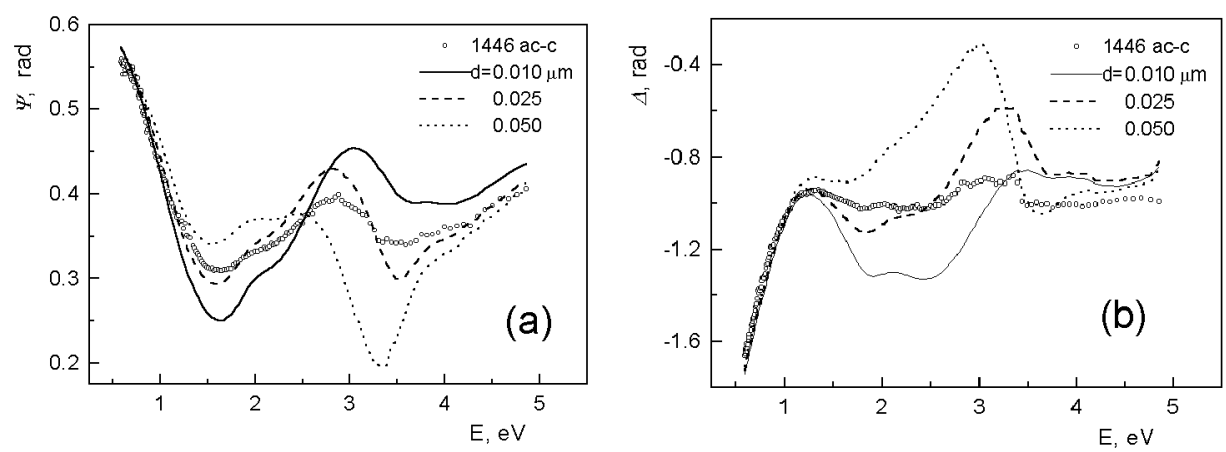

Fig. 2. Experimental (points) spectral dependence of ellipsometric parameters $\Psi$ (a) and $\Delta$ (b) for sample 1446 with (ac)-surface and $c$-axis of $\left(\mathrm{M}_{2} \mathrm{Cu}_{2} \mathrm{O}_{3}\right)_{m}\left(\mathrm{CuO}_{2}\right)_{n}$-type crystal in the plane of light incidence described by the model of complete surface layer of Bi-2212-type phase with a thickness of $0.01 \mu \mathrm{m}$ (solid curves), $0.025 \mu \mathrm{m}$ (dashed curves) and $0.05 \mu \mathrm{m}$ (dotted curves).

It should be noted that at large angles of incidence used $\left(\theta=70^{\circ}\right)$ the influence of $c$-component of dielectric tensor for Bi-2212 can be of importance, too. Additional ellipsometric investigations of the single crystals of Bi-2212 at different experimental configurations have shown that some optical feature at $3.5 \mathrm{eV}$ is observed in the spectra of the $c$-axis component. This contribution was neglected in the present model and can be responsible for some discrepancy between experimental and modeled spectra. Making use of the same set of fitting parameters, the experimental spectra of $\langle\varepsilon\rangle$ for another experimental geometry with $a$-axis in the plane of light incidence were also well described in the frame of this model. In this model the effective thickness of the surface Bi-2212-type layer was approximately equal to $25 \mathrm{~nm}$.

In the second model the $\left(\mathrm{M}_{2} \mathrm{Cu}_{2} \mathrm{O}_{3}\right)_{m}\left(\mathrm{CuO}_{2}\right)_{n}$ sample with the Bi-2212-type phase on the surface was considered in the model of effective medium assuming that the boundaries are parallel to the electric field. The PDF spectra were calculated using the following formula:

$$
\langle\varepsilon\rangle=\left(1-F_{\mathrm{Bi}-2212}\right)\left\langle\varepsilon_{\mathrm{IP}}\right\rangle+F_{\mathrm{Bi}-2212}\left\langle\varepsilon_{\mathrm{Bi}-2212}\right\rangle,
$$

where $\left\langle\varepsilon_{\mathrm{IP}}\right\rangle$ and $\left\langle\varepsilon_{\mathrm{Bi}-2212}\right\rangle$ are PDF for $\left(\mathrm{M}_{2} \mathrm{Cu}_{2} \mathrm{O}_{3}\right)_{m}\left(\mathrm{CuO}_{2}\right)_{n}$ and Bi-2212 phases, respectively, and $F_{\mathrm{Bi}-2212}$ is the fraction of the sample surface area covered by the Bi-2212-type phase of finite thickness. The contribution of the interface between Bi-2212 film and $\left(\mathrm{M}_{2} \mathrm{Cu}_{2} \mathrm{O}_{3}\right)_{m}\left(\mathrm{CuO}_{2}\right)_{n}$ was taken into account by Eqs. $(7,8)$. For 
film thickness $d_{\mathrm{Bi}}>0.4 \mu \mathrm{m}$ the contribution of the area covered by Bi-2212-type phase to the optical response is dominated by the optical properties of this secondary phase.

Figure 3 shows PDF $\langle\varepsilon\rangle$ calculated in the model of effective medium fitted to the experimental data for the sample 1446 in the same experimental configuration as in Fig. 2 along with the separate contributions of two phases. In this model the experimental data for the optical response of the samples with secondary surface phase were successfully described for both $(a c)$ and $(b c)$-planes.
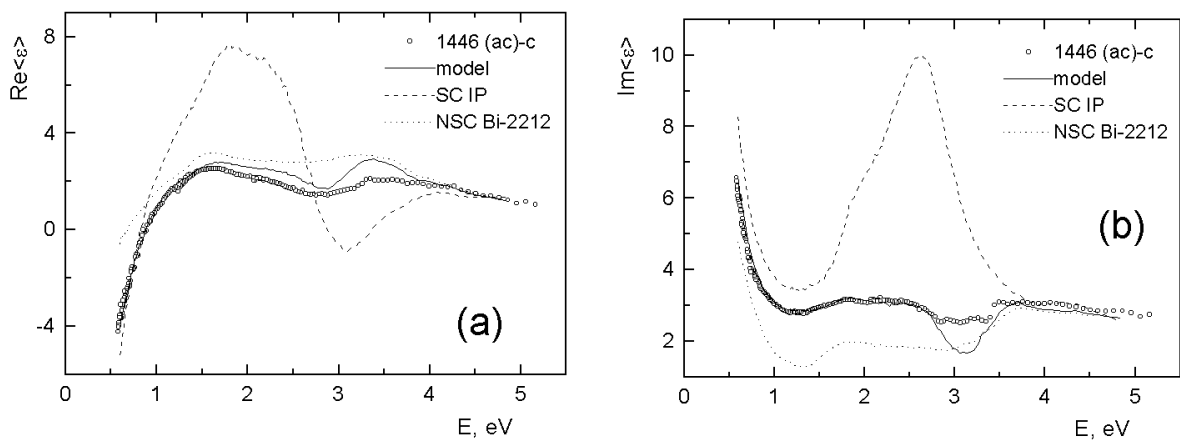

Fig. 3. Real (a) and imaginary (b) parts of the pseudodielectric function for as-grown (ac) surface of the sample 1446 with $c$-axis parallel to the plane of light incidence (circles) as compared with the data for clean $\left(\mathrm{M}_{2} \mathrm{Cu}_{2} \mathrm{O}_{3}\right)_{5}\left(\mathrm{CuO}_{2}\right)_{7}$ crystal 1317 (dashed curves) and Bi-2212 sample 1112 (dotted curves) and modeled spectra (solid curves) with parameters $F_{\mathrm{Bi}}=0.8$ and $d_{\mathrm{Bi}}=0.067 \mu \mathrm{m}$.

Taking into account the fitting provided in both models, the thickness of the complete film or islands was in the range of $0.02-0.07 \mu \mathrm{m}$. The surface area occupied by the Bi-2212-type phase in the samples 1446 and 800 was quite large as indicated by large values of $F_{\mathrm{Bi}}=0.8 \div 0.9$. It should be emphasized that in this model the film thickness and the $F_{\mathrm{Bi}}$-value are rather the features characterizing a total amount of the secondary phase.

\subsection{Magnetic studies}

The measurements of temperature dependences of magnetic moment at low magnetic field were carried out for the sample 1446. The obtained zero field cooled (ZFC) and field cooled (FC) magnetization dependences, $M(T)$, for as-grown and ion-etched samples are shown in Figs. $4 \mathrm{a}$ and $\mathrm{b}$ for three orientations of magnetic field. Significant differences, especially for $H \| b$ and $H \| c$, between the results for as-grown $\left(\mathrm{M}_{2} \mathrm{Cu}_{2} \mathrm{O}_{3}\right)_{m}\left(\mathrm{CuO}_{2}\right)_{n}(m / n=5 / 7)$ sample with a Bi-2212 depositions on its surface and for the same sample after ion-etching, are clearly seen.

The data obtained can be reliably interpreted assuming the presence of two phases in the sample under consideration. In particular, in the magnetization $M(T)$ 

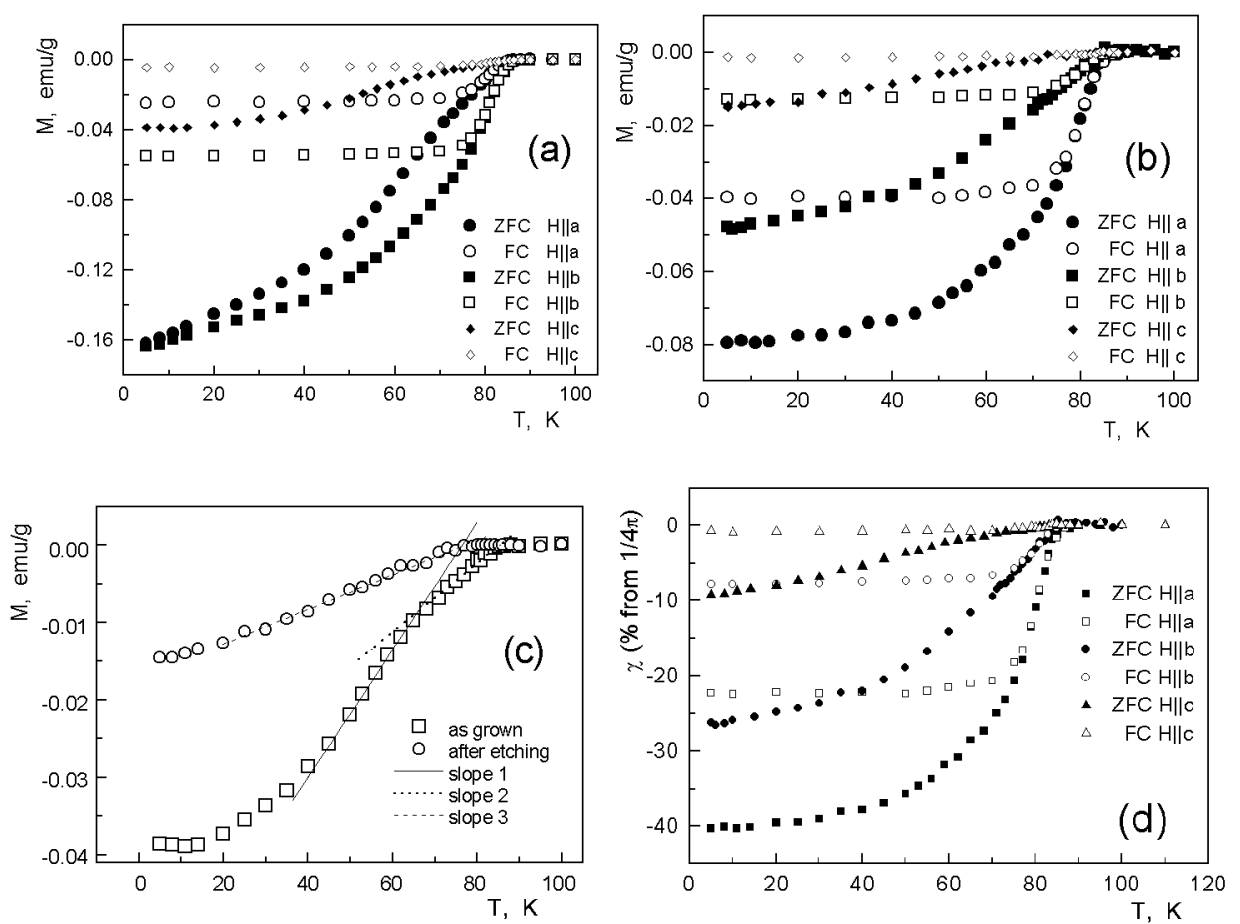

Fig. 4. Temperature dependences of ZFC and FC magnetization of the sample 1446 before (a) and after (b) the ion-etching with magnetic field $H=10$ Oe along three crystallographic axes; comparison of ZFC magnetization for as-grown and ion-etched sample at $H \| c$ (points are experimental data and lines correspond to transition slopes) (c) and temperature dependence of magnetic susceptibility for the ion-etched sample referred to ideal diamagnet at main orientations of magnetic field (d).

for as-grown sample shown in Fig. 4c for $H \| c$ there is a kink resulting from the contributions of two phases with different values of $T_{\mathrm{c}}$ (slope 1 , slope 2). A lower value of $T_{\mathrm{c}}$ (slope 1) well corresponds to that of the ion-etched sample (slope 3 ). On the other hand, a higher of these $T_{\mathrm{c}}$-values (slope 2), being equal to about $85 \mathrm{~K}$, well corresponds to $T_{c}$ of the $\mathrm{Bi}-2212$ phase. It is worth noting that demagnetizing fields for $H \| c$ can be neglected taking into account the sample dimensions $0.4 \times 0.3 \times 4.1 \mathrm{~mm}$ and $0.21 \times 0.2 \times 2.5 \mathrm{~mm}$ before and after etching, respectively.

Assuming (on the basis of XRD data) that the sample contains only one phase after etching, it was possible to calculate the susceptibility (with demagnetizing fields taken into account) shown in Fig. 4d. The $\chi(T)$ data for the etched sample regarding both absolute values and anisotropy are in good correspondence with the results obtained previously [12] for the $\left(\mathrm{M}_{2} \mathrm{Cu}_{2} \mathrm{O}_{3}\right)_{m}\left(\mathrm{CuO}_{2}\right)_{n}(m / n=5 / 7)$ samples without $\mathrm{Bi}$-2212-type phase. Qualitative comparison of the magnetization 
data presented in Figs. 4a and b suggests that beside the Bi-2212 layer on the one side of $(a c)$ plane observed in optical experiments, a presence of other forms of Bi-2212 depositions (drops or layer islands) on the other sample planes is probable. Though the latter contribution is difficult to estimate numerically, as a whole, the model of two phases qualitatively describes the main regularities observed in magnetic data.

\section{Concluding remarks}

The studies of $\left(\mathrm{M}_{2} \mathrm{Cu}_{2} \mathrm{O}_{3}\right)_{m}\left(\mathrm{CuO}_{2}\right)_{n}$ single crystals with the Bi-2212-type phase, which was formed on the sample surface and indicated by the structural investigations, have shown that the presence of such layer can be detected with a confidence by measuring the optical and magnetic properties. The presence of Bi-2212 phase on the crystal surface manifests itself by the change of the features in the optical spectra in the region of electronic excitations as well as by the change of the magnetization measured for different experimental configurations.

\section{Acknowledgments}

This work was partially supported by U.S.-CRDF (project No. 6422).

\section{References}

[1] N. Motoyama, T. Osafune, T. Kakeshita, H. Eisaki, S. Uchida, Phys. Rev. B 55, R3386 (1997).

[2] R. Szymczak, H. Szymczak, M. Baran, E. Mosiniewicz-Szablewska, L. Leonyuk, G.-J. Babonas, V. Maltsev, L. Shvanskaya, Physica C 311, 187 (1999).

[3] T. Osafune, N. Motoyama, H. Eisaki, S. Uchida, Phys. Rev. Lett. 78, 1980 (1997).

[4] G.-J. Babonas, L. Leonyuk, A. Reza, V. Maltsev, L. Dapkus, Supercond. Sci. Technol. 12, 128 (1999).

[5] M. Uehara, T. Nagata, J. Akimitsu, H. Takahashi, N. Mori, K. Kinoshita, J. Phys. Soc. Jpn. 65, 2764 (1996).

[6] L. Leonyuk, G.-J. Babonas, A. Vasilév, R. Szymczak, A. Reza, V. Maltsev, L. Ponomarenko, Czech. J. Phys. 46, (supplement S3), 1457 (1996).

[7] T. Nagata, M. Uehara, J. Goto, N. Komiya, J. Akimitsu, N. Motoyama, H. Eisaki, S. Uchida, H. Takahashi, T. Nakanishi, N. Mori, Phys. Rev. Lett. 81, 1090 (1998).

[8] T.M. Rice, S. Gopalan, M. Sigrist, Physica B 199\&200, 378 (1994).

[9] T. Nagata, M. Uehara, J. Goto, N. Komiya, J. Akimitsu, N. Motoyama, H. Eisaki, S. Uchida, H. Takahashi, T. Nakanishi, N. Mori, Physica C 282-287, 153 (1997).

[10] L. Leonyuk, G.-J. Babonas, V. Chernyshov, V. Rybakov, V. Maltsev, M. Baran, Acta Crystallogr. A 56, 149 (2000).

[11] B.V.Slobodin, A.A. Fotiev, A.S. Kosmynin, G.E. Shter, N.K. Garkushin, V.L. Balashov, A.S. Trunin, Sverkhprovodimost' 3, 523 (1990). 
[12] L. Leonyuk, G.-J. Babonas, R. Szymczak, H. Szymczak, M. Baran, A. Reza, V. Maltsev, L. Shvanskaya, V. Rybakov, Europhys. Lett. 45, 387 (1999); R. Szymczak, H. Szymczak, M. Baran, E. Mosiniewicz-Szablewska, L. Leonyuk, G.-J. Babonas, V. Maltsev, L. Shvanskaya, Physica C 311, 187 (1999).

[13] V. Maltsev, L. Leonyuk, G.-J. Babonas, R. Szymczak, A. Reza, J. Cryst. Growth 211, 501 (2000).

[14] V. Maltsev, L. Leonyuk, G.-J. Babonas, A. Reza, L. Dapkus, J. Cryst. Growth 225, 162 (2001)

[15] V. Maltsev, L. Leonyuk, G.-J. Babonas, A. Vetkin, A. Reza, J. Cryst. Growth 198/199, 626 (1999).

[16] L. Leonyuk, G.-J. Babonas, R. Szymczak, V. Maltsev, L. Shvanskaya, A. Reza, Physica C 337, 256 (2000).

[17] G.-J. Babonas, L. Leonyuk, A. Galickas, A. Reza, L. Shvanskaya, L. Dapkus, V. Maltsev, Supercond. Sci. Technol. 10, 496 (1997).

[18] D.E. Aspnes, J. Opt. Soc. Am. 70, 1275 (1980).

[19] R.M.M.A. Azzam, N.M. Bashara, Ellipsometry and Polarized Light, North-Holland, Amsterdam 1977.

[20] G.-J. Babonas, R. Dagys, V. Kregzde, L. Leonyuk, G. Pukinskas, A. Vetkin, Supercond. Sci. Technol. 5, 671 (1992). 